\title{
Vermicompost for Mitigation of Surfactant Contamination in Surface Water
}

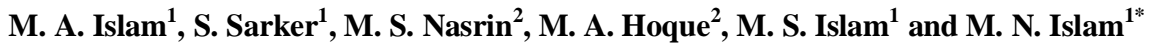 \\ ${ }^{1}$ Department of Chemistry, University of Rajshahi, Rajshahi-6205, Bangladesh \\ ${ }^{2}$ Department of Biochemistry and Molecular Biology, University of Rajshahi, Rajshahi-6205, \\ Bangladesh
}

Received 29 January 2020, accepted in final revised form 19 March 2020

\begin{abstract}
Surfactants are the most important pollutants of surface water which should be removed for the safety of aquatic life. The potentiality of vermicompost for the removal of surfactant contamination in surface water was studied by measuring surfactant concentration, $\mathrm{pH}$ and conductivity for nine days in six trials with different proportions of soil, vermicompost and phosphate keeping the surfactant concentration constant. The trials $T_{1}, T_{2}, T_{3}, T_{4}$ and $T_{5}$ were considered as simulated ponds and $\mathrm{T}_{0}$ as control. The surfactant concentration, electrical conductivity and $\mathrm{pH}$ were found to change upon the application of vermicompost. The surfactant degradation rate of vermicompost amended systems was significantly higher than the control system. Surfactant was almost completely depleted in vermicompost amended systems within the monitoring period. The presence of phosphate increases the surfactant removal efficacy of vermicompost. The $\mathrm{pH}$ values for vermicompost amended systems were almost constant near 7 . The electrical conductivity of vermicompost amended systems was found to increase with time whereas that for the control systems was almost constant. Therefore, vermicompost can be considered as an excellent amendment as they have the ability to remove surfactant in surface water correcting the $\mathrm{pH}$ and increasing the availability of nutrients of the systems.
\end{abstract}

Keywords: Electrical conductivity; pH; Surface water pollution; Surfactant mitigation; Vermicompost.

๑) 2020 JSR Publications. ISSN: 2070-0237 (Print); 2070-0245 (Online). All rights reserved.

doi: http://dx.doi.org/10.3329/jsr.v12i3.45220 $\quad$ J. Sci. Res. 12 (3), 411-417 (2020)

\section{Introduction}

Surface water pollution is one of the greatest challenges facing the world today. It began since industrial revolution, increasing day by day and causing serious damage to environment [1]. Surface water is polluted by various ways such as raw sewage, industrial waste, radiation spills, illegal dumping of substances, biological contamination, farm

Corresponding author: $\underline{\text { mnurulchem@gmail.com }}$ 
runoff and bacteria growth etc. Surfactants from wastewater are the most important pollutant of surface water. Surfactants can have poisonous effect in all types of aquatic life if they are present in sufficient quantities [2].

The degree of aquatic plants damage depends on the surfactant concentration. High concentration of surfactant in water bodies is related to algae and other microorganism's growth that decrease primary productivity of water bodies. Acute surfactant poisoning can lead to the cell structure damage by increasing cell permeability [3]. A certain toxicity of surfactants can also pass into the animal through animal feeding and skin penetration way. At high concentration, surfactants can enter the gills, blood, kidney, pancreas, gallbladder and liver, and produce aquatic toxicity effect [4].

Surfactant is a water-soluble component and it cannot be separated completely from contaminated water. To protect the food chain and aquatic life from the harmful effects of surfactant, surfactants in surface water is necessary to control. This can be achieved by controlling the use of surfactant in laundry process or by taking measures to remove the surfactant from surface water bodies. Surfactant removal processes include chemical and electrochemical oxidation, membrane technology, chemical precipitation, photocatalytic degradation, adsorption and various biological methods. Each has its merits and demerits in applications [5,6].

Vermicomposting is one of the best ways to dispose the waste not only due to its capacity of reducing the waste, but also due to its ability to remediate and amend the soil. Some researchers revealed that, vermicomposting acts as a potential material for $\mathrm{Cd}$ and $\mathrm{Ni}$ absorption in contaminated soil [7]. In our previous work, it was found that vermicompost can enhance the phosphorous adsorption capacity of soil [8]. We have also assumed that vermicompost can also be used for removing surfactants from surface water bodies like ponds, lakes etc. as it is rich in diversified microbes which may consume the surfactants in wastewater.

The objective of this study was to investigate the effect of vermicompost on surface water to mitigate the surfactant contamination from surface water and on the other physicochemical properties of water like $\mathrm{pH}$ and conductivity to improve the quality of water.

\section{Experimental}

\subsection{Materials}

Sodium dodecyl sulfate (SDS, purity, $99 \%$ ), methylene chloride (purity, $99.9 \%$ ), tin(II) chloride (purity, 97\%), $\mathrm{NaOH}$ (purity, $98 \%$ ), $\mathrm{NaCl}$ (purity, $99 \%$ ), $\mathrm{H}_{2} \mathrm{SO}_{4}$ (purity, $98 \%$ ), $\mathrm{KH}_{2} \mathrm{PO}_{4}$ (purity, $99.5 \%$ ), $\mathrm{HCl}$ (purity, $37 \%$ ), were procured from Loba Chemie Private Limited, India. Methylene blue (purity, $98.9 \%$ ) was obtained from Merck, Darmstadt, Germany. All the chemicals were used without further purification. Redistilled and deionized water was used for solution preparation. Working solutions were prepared by sequential dilution of each standard solution with ultrapure water. Soil sample was 
collected from non-cultivated area of Rajshahi University campus in Rajshahi, Bangladesh. The samples taken from the upper $15 \mathrm{~cm}$ soil layer were air-dried, ground and sieved through 2-mm sieve to increase the uniformity of the experiment and preserved in a polyethylene plastic packet. The particle size distribution of the used soil was $42.01 \%$ silt, $44.04 \%$ sand and $13.94 \%$ clay with texture grade of sandy loam. Vermicompost were collected from a home-based farm situated in Chapainawabganj district in Bangladesh. The moisture contents of soil and vermicompost were $20.67 \%$ and $75.28 \%$ respectively.

\subsection{Methods}

The potentiality of vermicompost on surfactant removal was studied using six trials with different proportions of soil, vermicompost and phosphate keeping the surfactant concentration constant. The change in the physicochemical properties of the samples was monitored by measuring surfactant concentration, $\mathrm{pH}$ and conductivity for nine days. Six experimental trials $\mathrm{T}_{0}, \mathrm{~T}_{1}, \mathrm{~T}_{2}, \mathrm{~T}_{3}, \mathrm{~T}_{4}$ and $\mathrm{T}_{5}$ were constructed in $3 \mathrm{~L}$ glass bottles among which $T_{1}, T_{2}, T_{3}, T_{4}$ and $T_{5}$ were considered as simulated ponds and $T_{0}$ as control. The ratio of surfactant (Surf.) to phosphate $(\mathrm{P})$ concentrations was chosen from the recent report on Surf Excel composition [9] and the ratio of soil to vermicompost (VC) was chosen from the report on the potentiality of organic fertilizers on phosphorous management [8]. The compositions of six experimental trials are shown in Table 1.

Table 1. Compositions of experimental trials.

\begin{tabular}{lcccc}
\hline \multicolumn{1}{c}{ Trials } & $\begin{array}{c}\text { Vol. of } \\
\text { solution*/L }\end{array}$ & $\begin{array}{c}\text { conc. of } \\
\mathrm{P} / \mathrm{ppm}\end{array}$ & Mass of soil/g & Mass of VC/g \\
\hline $\mathrm{T}_{\mathrm{o}}$ (Surf.) as Control & 2.0 & 0.0 & 0.0 & 0.0 \\
$\mathrm{~T}_{1}$ (Surf. + Soil) & 2.0 & 0.0 & 500.0 & 0.0 \\
$\mathrm{~T}_{2}$ (Surf. + VC) & 2.0 & 0.0 & 0.0 & 50.0 \\
$\mathrm{~T}_{3}$ (Surf. + VC + Soil) & 2.0 & 0.0 & 500.0 & 50.0 \\
$\mathrm{~T}_{4}$ (Surf. + P + VC) & 2.0 & 400.0 & 0.0 & 50.0 \\
$\mathrm{~T}_{5}$ (Surf. + P + VC + Soil) & 2.0 & 400.0 & 500.0 & 50.0 \\
\hline
\end{tabular}

*Aqueous solution of surfactant (1000 ppm)

A standard method $[10,11]$ was used for the estimation of surfactant content using UVvisible spectrophotometer, where methylene blue was used as cationic dye and methylene chloride as organic solvent. The methylene blue complexing solution of $100 \mathrm{~mL}$ in redistilled and deionized water was prepared by well mixing $3 \mathrm{~mL}$ of $1000 \mathrm{mg} / \mathrm{L}$ methylene blue stock solution, $4 \mathrm{~mL}$ of $3 \mathrm{M}$ sulphuric acid solution and $5 \mathrm{~g}$ of $\mathrm{KH}_{2} \mathrm{PO}_{4} \cdot \mathrm{H}_{2} \mathrm{O}$. $100 \mathrm{~mL}$ of washing solution was made by adding $0.7 \mathrm{~mL}$ of concentrated sulphuric acid and $5 \mathrm{~g}$ of $\mathrm{KH}_{2} \mathrm{PO}_{4} \cdot \mathrm{H}_{2} \mathrm{O}$ in redistilled and deionized water.

All sample solutions were diluted 50 times before analysis and the SDS standard solutions $(1,5,10,20,30$ and $40 \mathrm{mg} / \mathrm{L})$ from $100 \mathrm{mg} / \mathrm{L}$ standard SDS stock solution were prepared in redistilled and deionized water. Then $2 \mathrm{~mL}$ of diluted sample solution from each trial or SDS standard solution was taken in a vial. The $\mathrm{pH}$ of the solution was 
adjusted to 8.3 by adding drop wise sodium hydroxide or hydrochloric acid solution. To the solution, $0.5 \mathrm{~mL}$ of the methylene blue complexing solution and $2 \mathrm{~mL}$ of methylene chloride were added and the vial was immediately closed with the cap tightly. The solution was shaken for $20 \mathrm{sec}$. The anionic surfactant present in standard SDS solutions or trial solubilized in organic solvent through complex formation with the positively charged methylene blue by electrostatic interaction. The contents in the vial were allowed to stand for phase separation and the organic phase was collected into another vial using a long-tip pasteur pipette with a rubber bulb. For complete transfer of methylene bluesurfactant complex from aqueous phase to organic phase, three more extractions were performed using $2 \mathrm{~mL}$ of methylene chloride each time. The extracted organic phase was washed once with $5 \mathrm{~mL}$ of washing solution and the tracer of the methylene bluesurfactant complex in the washing solution was extracted with $2 \mathrm{~mL}$ of methylene chloride. The extracted organic phase was transferred to a $10 \mathrm{~mL}$ volumetric flask and made up to mark by methylene chloride. The organic phase was then analysed by UVvisible spectrophotometer at $652 \mathrm{~nm}$. A Shimadzu UV-1800 UV-visible spectrophotometer was used for UV-visible absorption measurement.

$\mathrm{pH}$ of the supernatant liquid of the trials was measured with the help of $\mathrm{pH}$ meter (Hanna Instruments, HI 2211). Before using, pH meter was calibrated according to manufacturer's instructions using the buffer at $\mathrm{pH} 4.00$ and 7.00 buffer. The conductivity was measured by a conductivity meter (Jenway Conductivity Meter 4310). The conductivity meter was calibrated and cell constant was determined with $0.1 \mathrm{M}$ and 0.01 $\mathrm{M}$ standard $\mathrm{KCl}$ solution.

\section{Results and Discussion}

Study on the potency of vermicompost for removing surfactant in water bodies was carried out by measuring surfactant concentrations of different trials prepared with varying proportions of soil, vermicompost and phosphate keeping the surfactant concentration constant. To check the environment of the systems, some physicochemical properties like $\mathrm{pH}$ and electrical conductivity were evaluated. The data obtained are summarized in Tables 2 and 3.

Table 2. Surfactant concentration of different aqueous systems.

\begin{tabular}{ccccccc}
\hline \multirow{2}{*}{ Trials } & \multicolumn{7}{c}{ Surfactant concentration/ppm } \\
\cline { 2 - 7 } & 1st day & 2nd day & 3rd day & 5th day & 7th day & 9th day \\
\hline $\mathrm{T}_{0}$ & $19.99 \pm 0.11$ & $19.95 \pm 0.12$ & $18.82 \pm 0.19$ & $18.25 \pm 0.17$ & $18.20 \pm 0.24$ & $17.61 \pm 0.11$ \\
$\mathrm{~T}_{1}$ & $16.94 \pm 0.09$ & $14.21 \pm 0.21$ & $13.61 \pm 0.25$ & $11.72 \pm 0.17$ & $9.92 \pm 0.18$ & $8.98 \pm 0.26$ \\
$\mathrm{~T}_{2}$ & $15.28 \pm 0.17$ & $12.88 \pm 0.16$ & $11.78 \pm 0.26$ & $10.22 \pm 0.27$ & $6.24 \pm 0.10$ & $2.34 \pm 0.17$ \\
$\mathrm{~T}_{3}$ & $15.82 \pm 0.17$ & $10.34 \pm 0.19$ & $8.37 \pm 0.18$ & $5.28 \pm 0.14$ & $2.60 \pm 0.09$ & $2.22 \pm 0.18$ \\
$\mathrm{~T}_{4}$ & $13.84 \pm 0.10$ & $10.28 \pm 0.30$ & $8.99 \pm 0.30$ & $7.73 \pm 0.27$ & $3.70 \pm 0.15$ & $2.56 \pm 0.16$ \\
$\mathrm{~T}_{5}$ & $13.39 \pm 0.09$ & $8.22 \pm 0.07$ & $6.94 \pm 0.14$ & $4.54 \pm 0.20$ & $3.11 \pm 0.18$ & $2.94 \pm 0.17$ \\
\hline
\end{tabular}

Values were determined as the means \pm SD of the concentrations calculated from three replicate measurements. 


\subsection{Surfactant concentration}

High surfactant concentration causes adverse effects on aquatic life. From this study, we found that the surfactant concentrations of all trials were decreased gradually with time (Table 2) and at 9th day, there were remarkable differences in surfactant removal extent among trials with and without vermicompost (Fig. 1). In absence of soil and vermicompost (Control, $\mathrm{T}_{0}$ ), the decreasing trend was not so significant (19.99 to 17.61 ppm) indicating the stability of surfactant in water. The decreasing tendency was increased (16.94 to $8.98 \mathrm{ppm})$ in presence of soil $\left(\mathrm{T}_{1}\right)$. Soil itself has the ability to degrade surfactant due to presence of microbes in it. In vermicompost containing trials $\left(\mathrm{T}_{2}-\mathrm{T}_{5}\right)$, the surfactant concentration was found to decrease rapidly. This may be due to adsorption of surfactant to the surface as well as microbial biodegradation in aerobic condition [12]. Replacement of soil with vermicompost $\left(\mathrm{T}_{2}\right)$ intensified the surfactant degradation rate (15.28 to $2.34 \mathrm{ppm}$ ). The surfactant concentrations of trials $\mathrm{T}_{1}$ and $\mathrm{T}_{2}$ were comparable to each other within first 5 days although the amount of adsorbent (500 $\mathrm{g}$ of soil) in $\mathrm{T}_{1}$ was much greater than $\mathrm{T}_{2}$ (50 g of vermicompost). However, the results of the succeeding days were better for the vermicompost containing trial $\left(\mathrm{T}_{2}\right)$. These results revealed that along with adsorption, microbial activity played an important role in surfactant degradation. This speculation was supported by the data obtained from $T_{3}$ in which the surfactant concentration was decreased rapidly compared to $\mathrm{T}_{1}$ although the difference in the amount of absorbent was not so significant.

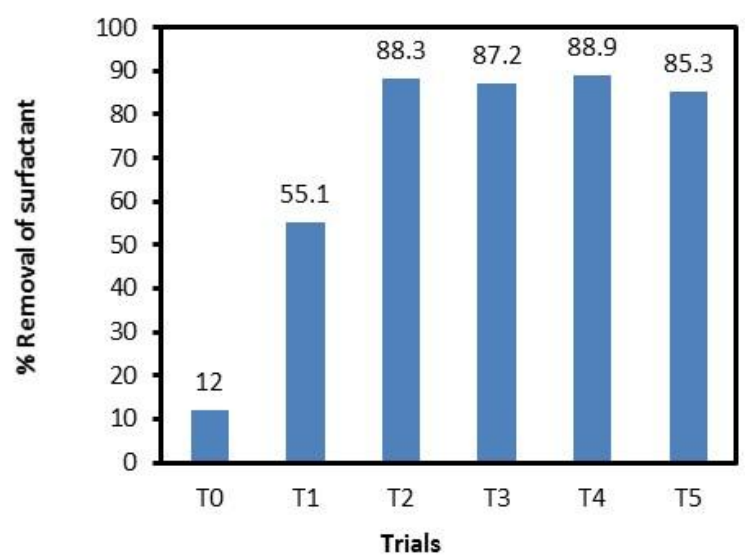

Fig. 1. Comparison of surfactant removing capacity among the trials at 9th day.

We have also studied the impact of phosphate on the surfactant degrading power of vermicompost as phosphate (sodium tripolyphosphate, STPP) is used as builder in commercial detergent. Interestingly, in presence of phosphate $\left(T_{4}\right.$ and $\left.T_{5}\right)$, the surfactant degrading capacity of the systems was enhanced as was evident from the data on 2 nd to 
7th days. As an essential component of nucleic acid, phosphate may help in increasing the microbial population.

\section{3. $\mathrm{pH}$ and electrical conductivity}

We have also monitored the effect of vermicompost on water environment by measuring some physicochemical properties such as $\mathrm{pH}$ and electrical conductivity (EC). The $\mathrm{pH}$ level directly affects the availability of essential soil nutrients for plant growth. For fresh water aquatic life, $\mathrm{pH}$ range is 6.5 to 9.0 [13] and the optimum uptake of most nutrients occurs near neutral $\mathrm{pH}$ 6.5-7.5 [14]. Therefore, buffering of a system is necessary for normal growth of aquatic life. In the present study, the $\mathrm{pH}$ was found to change upon the application of the vermicompost $\left(\mathrm{T}_{2}-\mathrm{T}_{5}\right)$ (Table 3$)$.

Table 3. $\mathrm{pH}$ and $\mathrm{EC}$ as a function of time for different aqueous systems.

\begin{tabular}{ccccccc|cccccc}
\hline \multirow{2}{*}{ Time/day } & \multicolumn{5}{c|}{$\mathrm{pH}$} & \multicolumn{5}{c}{$\mathrm{EC} /\left(\mu \mathrm{S} \mathrm{cm} \mathrm{cm}^{-1}\right)$} \\
\cline { 2 - 12 } & $\mathrm{T}_{0}$ & $\mathrm{~T}_{1}$ & $\mathrm{~T}_{2}$ & $\mathrm{~T}_{3}$ & $\mathrm{~T}_{4}$ & $\mathrm{~T}_{5}$ & $\mathrm{~T}_{0}$ & $\mathrm{~T}_{1}$ & $\mathrm{~T}_{2}$ & $\mathrm{~T}_{3}$ & $\mathrm{~T}_{4}$ & $\mathrm{~T}_{5}$ \\
\hline 1 & 7.27 & 7.31 & 7.04 & 7.06 & 7.02 & 6.99 & 409 & 233 & 527 & 343 & 1723 & 2450 \\
2 & 7.27 & 7.31 & 7.04 & 7.06 & 7.02 & 6.99 & 423 & 238 & 609 & 392 & 1845 & 2497 \\
3 & 7.26 & 7.30 & 7.04 & 7.05 & 7.01 & 7.00 & 453 & 243 & 652 & 441 & 1868 & 2548 \\
5 & 7.25 & 7.30 & 7.03 & 7.04 & 7.02 & 6.99 & 477 & 249 & 725 & 539 & 1898 & 2634 \\
9 & 7.24 & 7.27 & 7.02 & 7.04 & 7.01 & 6.98 & 491 & 260 & 811 & 742 & 1954 & 2702 \\
\hline
\end{tabular}

The $\mathrm{pH}$ values for vermicompost amended systems were found to be almost constant near $7(6.98-7.06)$ whereas that for other systems $\left(T_{0}\right.$ and $\left.T_{1}\right)$ were higher than $7(7.24-$ 7.31). Thus, vermicompost has the ability to support aquatic life by buffering the system.

There was difference in initial EC among the trials with and without phosphate. Obviously, trials containing phosphate showed much higher EC due to ions produced from $\mathrm{KH}_{2} \mathrm{PO}_{4}$. EC indicates the mineralization of organic matter in a system and serves as a measure of soluble nutrients [15]. The EC of vermicompost amended systems $\left(\mathrm{T}_{2}-\mathrm{T}_{5}\right)$ was gradually increased with time whereas that for the other systems $\left(T_{0}\right.$ and $\left.T_{1}\right)$, the change in EC was not so remarkable (Table 3). Increasing electrical conductivity with time is an evidence for nutrient mineralization. Therefore, in addition to removal of surfactant, vermicompost may increase the macro and micro nutrients availability in the aqueous systems. It was also found that the mineralization rate of vermicompost was not affected by the presence of phosphate in the systems.

\section{Conclusion}

Study on the potentiality of vermicompost as an amendment for the removal of surfactant contamination in surface water caused by household wastewater in laundry process was carried out by measuring surfactant concentration, $\mathrm{pH}$ and conductivity for nine days. The surfactant concentration, electrical conductivity and $\mathrm{pH}$ changed upon the application of the vermicompost. The surfactant degradation rate of vermicompost amended systems was significantly higher than the control system. Surfactant was almost completely 
depleted in vermicompost amended system within the monitoring period whereas almost $50 \%$ surfactant depletion was observed in the control system. The presence of phosphate increased the surfactant removal efficacy of vermicompost. The $\mathrm{pH}$ values for vermicompost amended systems were almost constant near 7 whereas that for control system were higher than 7. Vermicompost amended systems showed very high conductivity which were increased with time whereas those for the control systems were almost constant. Therefore, vermicompost can be considered as an excellent amendment as they have the ability to remove surfactant in surface water caused by wastewater in laundry process, correct the $\mathrm{pH}$ and increase the availability of nutrients of the systems.

\section{Acknowledgment}

The authors are grateful to the Faculty of Science, University of Rajshahi, Bangladesh for providing financial support to carry out this research work.

\section{References}

1. UN Educ. Sci. Cult. Organ. (UNESCO), The United Nations World Water Development Report 3: Water in a Changing World (Paris/New York: UNESCO/Berghahn Books, 2009).

2. J. Fawell and J. M. Nieuwenhuijsen, Br. Med. Bull. 68, 199 (2003). https://doi.org/10.1093/bmb/ldg027

3. T. B. Liu and Z. W. Feng, Environ. Poll.Contr. 19, 12 (1997).

4. C. L. Yuan, W. Zhou, and Y. S. Xie, J. Chin. Mass Spectros. Soc. 34, 215 (2013).

5. M. A. A. Hassan, S. Souabi, A. Yaacoubi, and M. Baudu, Int. J. Environ. Sci. Tech. 3, 327 (2006). https://doi.org/10.1007/BF03325941

6. T. K. Sen, J. Environ. Res. Develop. 6, 523 (2012).

7. B. C. More and S. S. Patole, J. Environ. Res. Develop. 7, 1047 (2012).

8. M. Seafatullah, M. A. Hoque, M. S. Islam, M. M. Islam, and M. N Islam, J. Sci. Res. 7, 167 (2015). https://doi.org/10.3329/jsr.v7i3.23756

9. Nur-E-Alam, M. M. Islam, M. N. Islam, F. R. Rima, and M. N. Islam, Environ. Sci. Pollut. Res. 23, 5468 (2016). https://doi.org/10.1007/s11356-015-5724-8

10. J. G. Ibanez, M. Hemandez-Esparza, C. Doria-Serrano, A. Fregoso-Infante, and M. M. Singh, Environmental Chemistry: Microscale Laboratory Experiments (Springer, New York, 2008). https://doi.org/10.1007/978-0-387-49493-7

11. S. K. Sar, C. Verma, P. K. Pandey, and A. Bhui, J. Chin. Chem. Soc. 56, 1250 (2009). https://doi.org/10.1002/jccs.200900180

12. K. Patel, A. K. Mungray, and Z. V. P. Murthy, J. Environ. Res. Develop. 3, 796 (2009).

13. British Columbia Approved Water Quality Guideline: Aquatic Life, Wild Life and Agriculture (Summery Report). Water Protection and Sustainability Branch (Ministry of Environment and Climate Change Strategy, 2018) pp. 28.

14. K. T. Osman, Soils: Principles, Properties and Management (Springer, Dordrecht, Heidelberg, New York, 2013) pp.109.

15. J. L. Smith and J. W. Doran, Measurement and Use of $\mathrm{pH}$ and Electrical Conductivity for Soil Quality Analysis, in Methods for Assessing Soil Quality, ed. J. W. Doran et al. (Soil Science Society of America, SSSA, Madison, 1996) 49. 